\title{
KRITERIA UNTUK MENENTUKAN HAK ASASI MANUSIA SEBAGAI “JUS COGENS" DALAM HUKUM INTERNASIONAL
}

\author{
A.A.A. Nanda Saraswati \\ Fakultas Hukum Universitas Brawijaya \\ Jl. M.T. Haryono 169 Malang \\ Email: anandasaraswati@yahoo.com
}

\begin{abstract}
In international law, there are norms which have the status or degree of jus cogens, therefore may not be violated, excluded or exempted under any circumstances. When a new norm of jus cogens in international law emerges, any treaty in conflict with that norm becomes invalid or void. This is what distinguishes jus cogens with other norms or principles in international law. This journal aims to determine the criteria for determining the principles of jus cogens and to analyze which human rights can be categorized as a jus cogens in international law. This journal is a normative research, using a statute and a conceptual approach. To determine the criteria of jus cogens, this paper analyzes that it should be done by looking at the formal aspects, namely the condition that forms the norm, and the substantive aspects, which are substantially the binding norrm itself. These two aspects are then used to determine which human rights can be catagorized as jus cogens. It can be seen from international recognition, the interpretation of language in international agreements, both in the preamble and the articles, the majority of countries that have ratified the agreement, and also the analysis of the decision or judicial body towards such international norms.
\end{abstract}

Key words: jus cogens, human rights, criteria, international law

\begin{abstract}
Abstrak
Dalam hukum internasional, terdapat beberapa norma yang memiliki status jus cogens, sehingga tidak dapat dilanggar, dikesampingkan atau dikecualikan dalam keadaan apapun. Bila muncul norma jus cogens yang baru dalam hukum internasional, maka perjanjian yang telah ada yang bertentangan dengan norma tersebut menjadi tidak sah atau batal. Hal inilah yang membedakannya dengan norma dan prinsip hukum internasional yang lain. Jurnal ini bertujuan untuk mengetahui kriteria untuk menentukan prinsip jus cogens dalam hukum internasional serta menganalisa hak asasi manusia apa saja yang dapat dikategorikan sebagai jus cogens dalam hukum internasional. Jurnal ini merupakan penelitian normatif, dengan pendekatan perundang-undangan (statute approach) dan pendekatan konseptual (conseptual approach). Untuk menentukan kriteria jus cogens, jurnal ini menganalisa bahwa hendaknya dilakukan dengan melihat aspek formal, yaitu sebuah kondisi yang membentuk norma tersebut, dan aspek substantif, dimana norrma tersebut memiliki substansi yang memaksa. Sedangkan untuk menentukan HAM apa saja yang merupakan jus cogens, maka dapat dianalisa berdasarkan aspek formal dan substantif diatas yang dapat dilihat dari pengakuan internasional, bahasa di dalam sejumlah perjanjian internasional, baik di dalam preambul maupun pasal-pasal, mayoritas negara yang telah meratifikasi perjanjian tentang norma jus cogens tersebut, dan juga analisis terhadap putusan badan atau peradilan internasional terkait norma tersebut.
\end{abstract}

Kata kunci: jus cogens, hak asasi manusia, kriteria, hukum internasional 


\section{Latar Belakang}

Dalam hukum internasional, "jus cogens" sering diartikan sebagai norma yang bersifat memaksa dan dianggap memiliki kedudukan tertinggi atau sumber utama (primary source) dari norma-norma yang mengatur hubungan internasional. Dalam hal ini, terdapat pandangan bahwa ada norma-norma dalam hukum internasional yang memiliki status atau derajat jus cogens, sehingga tidak dapat dikesampingkan atau dikecualikan dalam keadaan apapun. ${ }^{1}$ Sehingga dalam hal terjadinya pertentangan antara suatu jus cogens dengan norma lainnya (yang bukan jus cogens), maka norma yang memiliki derajat jus cogens itulah yang harus diutamakan, tanpa mempersoalkan sumber dari norma tersebut, tanpa mempersoalkan apakah norma tersebut terbentuk sebelum atau sesudah norma jus cogens yang ada, dan tanpa mempersoalkan apakah norma lain tersebut lebih spesifik dari norma jus cogens. ${ }^{2}$

Definisi tentang jus cogens akhirnya pertama kali diwujudkan dalam sebuah instrumen formal melalui Konvensi Wina tahun 1969 tentang Hukum Perjanjian Internasional, ${ }^{3}$ yang telah ditetapkan juga di dalam Konvensi Wina tahun 1986 tentang
Hukum Perjanjian Internasional antara negara dan organisasi internasional dan antar organisasi internasional. ${ }^{4}$ Definisi jus cogens dalam konvensi tersebut berbunyi:

A peremptory norm of general international law is a norm accepted and recognized by the international community of States as a whole as a norm from which no derogation is permitted and which can be modified only by a subsequent norm of general international law having the same character. ${ }^{5}$

Pasal di dalam Konvensi Wina diatas menganggap bahwa jus cogens atau peremptory norm sebagai norma dasar hukum internasional yang diterima dan diakui oleh negara-negara sebagai komunitas internasional secara keseluruhan. Jus cogens tersebut tidak boleh dilanggar oleh norma lainnya dan hanya dapat dimodifikasi oleh suatu norma dasar hukum internasional yang mempunyai sifat yang sama. Definisi tersebut jelas memperlihatkan sifat dari norma jus cogens yaitu normanya harus merupakan norma yang berlaku secara umum terhadap semua sistem hukum yang ada; normanya harus diterima dan diakui oleh komunitas internasional yaitu negara, secara eksplisit; dan normanya tidak dapat diturunkan dalam

1 Ian Brownlie, Principles of Public International Law, Fifth Edition, (New York: Clarendon Press, 1998), p. 515.

2 M. Akehurst, The Hierarchy of the Sources of International Law, XLVII BYIL, p. 281 di dalam Prof. Dr. G. J. H. Van Hoof, Rethinking the Sources of International Law, authorized translation from English language, (Bandung: Yayasan Hak Asasi Manusiam Demokrasi dan Supremasi Hukum, 2000), hlm. 310.

3 The Vienna Convention on the Law of Treaties 1969, Pasal 53.

4 The Vienna Convention on the Law of Treaties Between States and International Organizations or Between International Organizations, 1986, UN Doc. A/Conf. 129/15 (1986). Art. 53.

5 Vienna Convention on the Laws of Treaties, 1986, Pasal 53. 
keadaan apapun dan hanya dapat dimodifikasi oleh norma lain dalam hukum internasional yang memiliki karakter sama.

Ketiga sifat norma jus cogens tersebut mengklasifikasikan jus cogens sebagai norma yang tidak dapat dilanggar. Atau dengan kata lain ketika sebuah prinsip dalam hukum internasional telah mencapai derajat jus cogens, maka prinsip tersebut tidak dapat dikecualikan dalam keadaan apapun. Bahkan, bila ada norma peremptory baru muncul dalam hukum internasional, maka perjanjian-perjanjian yang telah ada yang bertentangan dengan norma tersebut menjadi tidak sah atau batal. Hal inilah yang membedakannya dengan norma dan prinsipprinsip hukum internasional yang lain. Bila dibandingkan dengan pembentukan hukum kebiasaan internasional, yang mensyaratkan praktek umum yang diterima sebagai hukum, pasal 53 Konvensi Wina diatas mensyaratkan bahwa norma jus cogens terbentuk bila norma tersebut diterima dan diakui oleh masyarakat internasional, khususnya negara, secara keseluruhan. Artinya, bahwa sebuah peremptory norm harus diterima oleh seluruh komunitas internasional. Tentu persyaratan pembentukan norma jus cogens ini lebih tinggi daripada persyaratan pembentukan hukum kebiasaan internasional dimana dalam hukum kebiasaan internasional, cukup mayoritas negara saja yang perlu menyetujui praktek umum tersebut. Hal ini dapat dipahami karena dalam hukum kebiasaan internasional, masih dimungkinkan terdapat negara yang menolak secara terus menerus praktek kebiasaan yang ada, yang sering disebut sebagai persistent objector. Dimana terhadap norma jus cogens, karena karakteristiknya yang bersifat memaksa dan non-derogable, maka tidak dimungkinkan sama sekali adanya persistent objector ${ }^{6}$ Itulah sebabnya ada yang menyebut bahwa opinio juris yang berlaku pada hukum kebiasaan internasional, harus berlaku juga pada jus cogens, tetapi bersifat"double opinio juris." ${ }^{7}$

Namun, ternyata sangat sulit untuk mengidentikasi suatu ketentuan hukum yang memiliki derajat jus cogens. Meskipun mayoritas negara peserta Konvensi Wina 1969 menerima konsep jus cogens sebagai norma yang memaksa, namun definisi, ruang lingkup dan kandungan konsep tersebut tidak (belum) jelas. Konvensi tersebut juga tidak memberikan daftar tindakan yang masuk kategori pelanggaran jus cogens. ${ }^{8}$ Salah satu pendapat mengatakan bahwa agar sebuah norma dapat menjadi jus cogens maka hendaknya memenuhi dua aspek yaitu aspek formal, yaitu sebuah kondisi yang membentuk

6 Hugh Thirlway, The Sources of International Law, (Foundation of Public International Law: Oxford University Press, 2014), p. 159.

7 Lihat Linderfalk, Legal Discourse Gone Awry: Why the Scholarly Debate on the Legality of Operation Enduring Freedom Was Poor Science, 2008 di dalam Ulf Linderfalk, "The Effect of Jus Cogens Norms: Whoever Opened Pandora's Box, Did You Ever Think About the Consequences?", The European Journal of International Law Vol. 18 No.5, (2008): 862, diakses 23 Pebruari 2016, doi: 10.1093/ejil/chm044.

8 Sefriani, Hukum Internasional: Suatu Pengantar, (Jakarta: RajaGrafindo Persada, 2009), hlm. 69. 
norma tersebut, dan aspek substantif, dimana norrma tersebut memiliki substansi yang memaksa.

Bila kita mengidentifikasi sejumlah kesepakatan dan perjanjian internasional, terlihat bahwa hak asasi manusia (HAM) memang merupakan salah satu isu penting dan universal sehingga hak-hak tersebut harus diutamakan dalam hubungan antar negara. Ketentuan non-derogable yang dikandungnya dan sifatnya yang universal terkadang dianggap merefleksikan norma jus cogens. Hal ini menimbulkan pertanyaan selanjutnya yaitu apakah semua HAM dapat dikategorikan sebagai norma jus cogens?

Norma-norma HAM, termasuk hak-hak sipil, politik, ekonomi, sosial maupun hak budaya lainnya memang dianggap sebagai norma yang bersifat non-derogable, namun sifat non-derogable tersebut tidak langsung dapat membuatnya memiliki derajat sebagai jus cogens. Hal ini memperlihatkan bahwa sulit untuk membedakan atau memisahkan norma jus cogens dari HAM pada umumnya.

Hingga saat ini, masyarakat internasional yang tidak mempunyai badan legislatif pusat seperti halnya negara, belum mampu menetapkan kriteria-kriteria yang dapat mengidentifikasi norma peremptory, agar dapat berlaku dan dan diterima dan ditaati oleh semua negara khususnya, dan masyarakat internasional pada umumnya di dunia tanpa terkecuali. Banyak kesulitan untuk menjawab seputar haruskah fungsi identifikasi ini dilaksanakan hanya melalui instrumen konvensi atau perjanjian mulatilateral yang membentuk hukum, ataukah norma jus cogens berkembang melalui proses yang sama dengan kaidah-kaidah hukum kebiasaan internasional. ${ }^{9}$ Prosedur normatif untuk menciptakan prinsip fundamental tersebut, dan cara agar negara-negara mau terikat secara hukum terhadap prinsip tersebut tentu masih menjadi sebuah tantangan bagi masyarakat internasional saat ini. ${ }^{10}$ Karena pada dasarnya, jangan sampai ketiadaan prosedur yang jelas terkait cara mengindentifikasi kriteria jus cogens ini malah akan membahayakan berlakunya hukum internasional yang dapat berakibat pada munculnya konflik yang didasarkan pada kepentingan politik negaranegara.

Berdasarkan latar belakang diatas, yang menjadi permasalahan dalam jurnal ini adalah:

1. Apakah kriteria untuk menentukan prinsip jus cogens dalam hukum internasional?

2. Prinsip hak asasi manusia apa yang dapat dikategorikan sebagai jus cogens dalam hukum internasional?

Jurnal ini merupakan penelitian normatif, dengan menggunakan pendekatan perundangundangan (statute approach) dan pendekatan konseptual(conseptualapproach). Pendekatan perundang-undangan dilakukan dengan menganalisa berbagai perjanjian internasional yang terkait dengan jus cogens untuk

9 J.G Starke, Pengantar Hukum Internasional, Edisi Ke-Sepuluh, (Jakarta: Sinar Grafika, 1995), hlm. 67.

10 Gennady Danilenko, “International Jus Cogens: Issues of Law Making”, European Journal of International Law, Vol. II, No. 1, (1991): 2. 
memahami kandungan filosofi di dalamnya. Untuk mendukung pengkajian agar lebih komprehensif digunakan pula pendekatan konseptual, yaitu mempelajari pandangan, doktrin, konsep dan asas-asas hukum agar dapat membangun suatu argumentasi hukum dalam memecahkan isu yang dihadapi.

\section{Pembahasan}

\section{A. Kriteria untuk Mengidentifikasi Jus Cogens}

Seperti yang telah kita bahas diatas, bahwa komunitas internasional, yang tidak mempunyai badan legislatif pusat seperti halnya negara, belum mampu menetapkan kriteria-kriteria yang dapat mengidentifikasi norma peremptory, agar dapat berlaku dan terikat kepada semua negara di dunia tanpa terkecuali. Banyak kesulitan untuk menjawab seputar haruskah fungsi identifikasi ini dilaksanakan hanya melalui instrumen konvensi atau perjanjian mulatilateral yang membentuk hukum, ataukah norma jus cogens berkembang melalui proses yang sama dengan kaidah-kaidah hukum kebiasaan internasional. ${ }^{11}$

Kriteria untuk menentukan jus cogens memang akan terus berkembang dengan seiringnya waktu, doktrin yang muncul dan juga ketaatan negara. Untuk menentukan kriteria norma peremptory, dapat dilakukan dengan melihat aspek formal, yaitu sebuah kondisi yang membentuk norma tersebut, dan aspek substantif, dimana norrma tersebut memiliki substansi yang memaksa.

Ada tujuh kriteria dari segi formal untuk menentukan norma peremptory, yang menurut Lon Fuller, merupakan seperangkat "desiderata" yang harus dimiliki oleh norma hukum, terlepas dari tujuan substantif yang dimilikinya. ${ }^{12}$

1. Pertama, norma peremptory harus mewujudkan prinsip-prinsip umum dan universal, ${ }^{13}$ dan bukan norma-norma ad hoc.

2. Kedua, norma peremptory harus bersifat publik, ${ }^{14}$ agar negara-negara sebagai perwakilan dari rakyatnya, dapat mengetahui dan menyesuaikan kebijakan dan tindakan mereka sesuai dengan norma tersebut.

3. Ketiga, norma jus cogens harus layak dilakukuan, dalam arti norma ini bukan merupakan norma yang mustahil untuk dilakukan. Misalnya, negara yang sangat

11 J.G Starke, Pengantar Hukum Internasional, Edisi Ke-Sepuluh, (Jakarta: Sinar Grafika, 1995), hlm. 67.

12 Lon Fuller, The Morality of Law, rev. edn (New Haven: Yale UP, 1969), di dalam Evan J. Criddle \& Evan FoxDecent, "A Fiduciary Theory of Jus Cogens", The Yale Journal of International Law, Vol. 34, (2009): 361-362.

13 Ian Sinclair, The Vienna Convention on the Law of Treaties, (England: Manchester University Press, 1973), p.126; Lihat juga Ulf Linderfalk, “The Effect of Jus Cogens Norms: Whoever Opened Pandora's Box, Did You Ever Think About the Consequences?", The European Journal of International Law Vol. 18 No.5, (2008): 860, diakses 23 Pebruari 2016, doi: 10.1093/ejil/chm044.

14 Merlin Magallona, "The Concept of Jus Cogens in the Vienna Convention on the Law of the Treaties", Phillippine Law Journal, Vol. 51, (1976): 521. 
"miskin, dimana kemiskinan mengakar dimana-mana, tidak dapat diharapkan untuk menghapus atau memperbaiki kondisi tersebut secara kilat. Namun, negara yang mengizinkan pelaksanaan perbudakan, dapat diminta untuk segera menghapuskan kebijakan tersebut.

4. Keempat, subyek atau tujuan dari norma tersebut harus jelas dan tegas, oleh karena tujuannya untuk memberikan kriteria keadilan yang bersifat publik yang mampu untuk membimbing atau membatasi tindakan negara. Larangan perbudakan, contohnya, merupakan norma yang jelas dan tegas, sementara larangan eksploitasi kurang jelas. ${ }^{15}$

5. Kelima, norma peremptory sebaiknya konsisten, ${ }^{16}$ baik secara internal maupun secara lebih luas terhadap norma jus cogens. Norma peremptory yang tidak konsisten, atau yang saling bertentangan satu samalain, memberikanketidakjelasan dan bahkan tidak memberikan bimbingan apa-apa kepada negara untuk menjamin tuntutan hukum atas rakyatnya.

6. Keenam, norma jus cogens sebaiknya bersifat prospektif daripada retroaktif, karena negara-negara tidak dapat memutar kembali waktu dan membawa tindakan mereka kembali agar sesuai dengan norma yang ada. Hal ini tidak mengesampingkan munculnya norma peremptory yang membutuhkan perbaikan karena kesalahan di masa lampau, karena norma tersebut masih akan berlaku terhadap negara secara prospektif, yang dapat memberikan sanksi-sanksi tertentu di kemudian hari.

7. Dan terakhir, seperangkat norma peremptory sebaiknya tetap bertahan secara stabil (relatif) selama periode waktu tertentu agar negara-negara dapat merencanakan tindakannya dan mengimpementasikan kebijakankebijakannya berdasarkan kerangka hukum internasional yang stabil. ${ }^{17}$

Singkat kata, kriteria formal memastikan bahwa norma peremptory merupakan sebuah prinsip umum yang memiliki sifat publik, layak, jelas, konsisten, prospektif dan stabil, yang dapat digunakan oleh negara-negara untuk mengatur dan merepresentasikan rakyatnya. Norma yang bertentangan dengan prinsip-prinsip ini dapat mengganggu tindakan yang hendak dilakukan oleh sebuah negara atau bahkan menggagalkan tindakan tersebut, yang berdampak pada tidak adanya justifikasi atas tindakan tersebut.

Dengan adanya kriteria formal untuk menentukan norma jus cogens, tidak berarti kriteria tersebut cukup. Ada norma-norma yang memiliki kriteria formal tersebut

15 Lon Fuller, op.cit., p. 64.

16 Antonio Cassese and Joseph Weiler, Change and Stability in International Law Making, (Berlyn, Jerman: de Gruyter GmbH, 1988), p. 112.

17 Joost Pauwelyn, Conflict of Norm in Public International Law, How WTO Law Relates to Other Rules of International Law, (Cambridge: Cambridge University Press, 2003), p. 106. 
tetapi tidak bisa (atau belum bisa) disebut sebagai norma peremptory. Kriteria ini lebih merupakan aspirasi moral daripada kewajiban hukum yang tegas. Untuk itu dibutuhkan kriteria dari aspek lain untuk melengkapi konsep ini, yaitu kriteria substantif.

Terdapat lima kriteria substantif, dimana kriteria ini berhubungan dengan struktur maupun isi, yaitu: ${ }^{18}$

1. Pertama, adalah integrity, dimana jus cogens merupakan prinsip integritas.

Artinya bahwa norma peremptory harus memiliki tujuan yang mendatangkan kebaikan untuk masyarakat.

2. Kriteria kedua yang harus dimiliki oleh norma peremptory adalah "principle of formal moral equality", ${ }^{19}$ yang berarti bahwa norma tersebut memperlakukan orang sebagai moral yang setara. Prinsip ini menekankan "fairness" atau keadilan diantara para individu ketika negara bertindak.

3. Ketiga adalah "principle of solicitude", ${ }^{20}$ yaitu bahwa norma peremptory harus memperhatikan kepentingan subyek hukum yang sah.

Bila kita perhatikan, kriteria substantif bersama dengan kriteria formal sangat terkait dengan sebagian besar HAM. Hak-hak sipil dan politik, ekonomi, sosial maupun hak budaya memang cocok dimasukan ke dalam kerangka analitikal ini. Kebebasan berekspresi dan hak untuk bekerja, misalnya, sesuai dengan kriteria formal, memiliki tujuan yang baik dan konsisten dengan prinsip kesetaraan moral. Sehingga terlihat bahwa sangat susah untuk membedakan atau memisahkan norma jus cogens dari HAM pada umumnya, karena terlihat bahwa kriteria tersebut lebih condong kepada HAM umum dan bukan norma-norma peremptory secara khusus.

Bila para ahli berdiskusi tentang jus cogens, maksud mereka adalah norma yang bersifat memaksa dan tidak dapat dikesampingkan atau "non-derogable" terlepas adanya persetujuan negara atau tidak. ${ }^{21}$ Untuk itu tidak semua HAM dapat dikategorikan sebagai norma memaksa. ${ }^{22}$ Contohnya adalah larangan untuk berpidato tentang kebencian, yang menurut beberapa pihak membatasi kebebasan untuk berekspresi. Contoh lain misalnya adalah kebebasan untuk berasosiasi. Tentu kebebasan ini tidak dimaksudkan untuk berasosiasi untuk tujuan konspirasi melakukan tindak pidana. Atau hak untuk mendapatkan privasi. Hak ini tidak dapat dijamin bila ada ada kemungkinan atau dasar-dasar yang jelas bahwa individu tersebut telah melakukan suatu kejahatan. ${ }^{23}$

Kebebasan berekspresi, kebebasan

18 Lon Fuller, The Morality of Law, (New Haven: Yale UP, 1969) di dalam Evan J. Criddle \& Evan Fox-Decent, "A Fiduciary Theory of Jus Cogens", The Yale Journal of International Law, Vol. 34, (2009): 361-363.

19 Ken Coghill, Charles Stamphord, Tim Smith, Fiduciary Duty and the Atmospheric Trust, (England: Ashgate Publishing Limited, 2012), p. 258.

20 Ibid.

21 Vienna Convention on the Law of Treaties art. 53.

22 Michelle Foster, International Refugee Law and Socio Economic Rights, (UK: Cambride University Press, 2007), p. 180.

23 Evan J. Criddle \& Evan Fox-Decent, op.cit., p. 364. 
berasosiasi, maupun hak untuk mendapatkan privasi merupakan sebuah norma yang bersifat mandatory atau memaksa. ${ }^{24}$ Namun ketiga norma tersebut tidak berhubungan secara langsung dengan kepentingan masyarakat yang luas dan dapat dibatasi berdasarkan kepentingan publik. Dan ketiga kriteria substantif di atas berasal dari karakter umum dari kekuasaan negara dan kewajiban umum terhadap rakyat, padahal kriteria substantif ini seharusnya lebih berisi tentang kewajiban negara untuk menjamin dan memastikan tatanan hukum. Untuk itulah diperlukan kriteria yang keempat dan kelima.

4. Kriteria substantif keempat terkait jus cogens adalah "principle of fundamental equal security" yang merupakan norma yang penting untuk kesetaraan keamanan yang fundamental dari individu. Negara tidak dapat menyimpang dari norma yang digunakan untuk mencapai tatanan hukum yang aman tersebut. Prinsip inilah yang dapat memberikan kita gambaran terkait perbedaan antara norma yang derogable dan non derogable.

5. Kelima adalah rule of law. Penghormatan terhadap norma tersebut tidak dapat dihapuskan dari kemampuan negara untuk melakukan tindakan-tindakan yang menjamin atau mengamankan legalitas demi kepentingan bersama. Artinya bahwa bahwa semua tindakan negara harus memiliki dasar hukum, baik dari Undang-undang, pengadilan, putusan hakim yang adil dan dapat dihukum bila perbuatan tersebut telah diatur sebelumnya. ${ }^{25}$

Tabel 1. Kriteria untuk Mengidentifikasi Jus Cogens

\begin{tabular}{clcc}
\hline No. & Kriteria Spesifik Jus Cogens & Karakter & Pemenuhan Kriteria \\
\hline 1. & Generality & Formal & Necessary \\
2. & Publicity & Formal & Necessary \\
3. & Feasibility & Formal & Necessary \\
4. & Clarity & Formal & Necessary \\
5. & Consistency & Formal & Necessary \\
6. & Prospectivity & Formal & Necessary \\
7. & Stability & Formal & Necessary \\
8. & Integrity & Substantive & Necessary \\
9. & Formal moral equality & Substantive & Necessary \\
10. & Solicitude & Substantive & Necessary \\
11. & Fundamental equal security & Substantive & Sufficient \\
12. & Rule of Law & Substantive & Sufficient \\
\hline
\end{tabular}

Sumber: Lon Fuller, The Morality of Law, New Haven: Yale UP, 1969

24 International Covenant on Civil and Political Rights art. 4, Dec. 16, 1966, S. EXEC. DOC. E, 95-2 (1978), 999 U.N.T.S. 171, 174, European Convention for the Protection of Human Rights and Fundamental Freedoms art. 15, Nov. 4, 1950, 213 U.N.T.S. 221, 233-34.

25 Evan J. Criddle \& Evan Fox-Decent, op.cit., p. 367. 
Tabel 1. menunjukan bahwa terdapat 12 kriteria yang dapat digunakan untuk mengidentifikasi jus cogens, yaitu 7 kriteria yang bersifat formal (bersifat umum, bersifat publik, layak untuk dilakukan, jelas dan tegas, konsisten, prospektif, dan stabil) dan 5 kriteria substantif (memiliki integritas, adil, memperhatikan kepentingan subyek hukum yang sah, setara, memiliki dasar hukum). 10 kriteria pertama perlu dimiliki oleh sebuah norma untuk menjadi jus cogens, sedangkan 2 kriteria terakhir wajib dimiliki oleh sebuah norma untuk menjadi jus cogens.

Dari berbagai penjelasan di atas, terlihat bahwa norma-norma HAM di atas memang merupakannormayang bersifatnon-derogable, yaitu norma yang tidak dapat dikesampingkan atau tidak dapat diabaikan, namun hal tersebut tidak langsung membuatnya memiliki sifat atau derajat sebagai jus cogens. Sehingga, pertanyaan selanjutnya adalah HAM apa saja yang dapat dikategorikan sebagai norma jus cogens? Berikut adalah analisanya.

\section{B. Hak Asasi Manusia sebagai Jus Cogens}

Berakhirnya Perang Dunia II merupakan suatu momentum penting bagi perkembangan HAM secara internasional. Pembentukan PBB beserta prinsip-prinsip di dalam Piagamnya, bersama dengan proses dekolonisasi, telah membuat HAM sebagai salah satu prinsip utama dan fundamental dalam hukum internasional, dimana nilai yang dikandungnya tidak dapat diabaikan begitu saja, dan harus diutamakan dalam hubungan antarnegara. ${ }^{26}$

Pertanyaan yang kemudian timbul adalah apakah semua norma HAM dapat dikategorikan sebagai norma jus cogens? Berdasarkan kriteria yang telah di bahas sebelumnya, untuk menentukan hak asasi manusia apa saja yang merupakan norma jus cogens, maka analisis berikut dilakukan berdasarkan kriteria menurut Lon Fuller yang mencakup aspek formal dan aspek substantif. Selain itu analisa juga disempurnakan dengan melihat bahasa yang terkandung di dalam sejumlah konvensi (baik di dalam preambule maupun pasal-pasal, yang mengindikasikan norma tersebut kedudukannya "lebih tinggi" dibandingkan dengan norma lain), tulisantulisan para ahli serta doktrin-doktrin hukum yang berkembang, serta praktek negara yang mengakui dan menerima norma tersebut maupun dari putusan peradilan dan tribunal internasional, ${ }^{27}$ seperti pendapat serta putusan yang dikeluarkan oleh Mahkamah Internasional atau ICJ, ${ }^{28}$ dan juga badan atau peradilan internasional lainnya.

26 Stefan Krichner, The Human Rights Dimensions of International Peace and Security: Humanitarian Intervention after 9/11, 2004, p. 1.

27 Laurence Boission de Chazaurnes, Philippe Sands, International Law, The International Court of Justice and Nuclear Weapons, (Cambridge: Cambridge University Press, 1999), p. 190.

28 Reservation to the Convention on the Prevention and Punishment of the Crima of Genocide, Advisory Opinion ICJ Reports, 1951, p.15. 


\section{Norma HAM tentang larangan melakukan genosida}

Larangan melakukan genosida yang diatur di dalam Convention on the Prevention and Punishment of the Crime of Genocide. Kejahatan genosida dideskripsikan sebagai "crimes of crimes. ${ }^{29}$

Berdasarkan pasal pertama konvensi tersebut dinyatakan bahwa genosida yang dilakukan baik pada waktu perang maupun damai adalah kejahatan berdasarkan hukum internasional yang harus dicegah dan di tindak, sebagaimana di atur sebagai berikut: "The Contracting Parties confirm that genocide, whether committed in time of peace or in time of war, is a crime under international law which they undertake to prevent and punish." Adapun yang dimaksud dengan genosida menurut ketentuan Pasal 2 konvensi tersebut adalah tindakan-tindakan yang dimaksudkan untuk menghancurkan, sebagian atau seluruhnya, suatu bangsa, etnis, ras atau kelompok-kelompok agama.

Bila diperhatikan, di dalam Konvensi Genosida tersebut para pihak disebut dengan istilah contracting parties, sehingga dapat diinterpretasi bahwa definisi dan juga kewajiban untuk mencegah praktek genosida hanya berlaku terbatas pada para pihak konvensi saja, yaitu negara-negara yang telah meratifikasinya. Hal ini mungkin terdengar kontradiktif karena sesuai pembahasan di atas bahwa norma jus cogens terikat semua negara, meskipun tanpa persetujuan negara. Namun, bila kita lihat pada preambul konvensi tersebut, disebutkan bahwa genosida merupakan kejahatan di bawah hukum internasional dan bertentangan dengan spirit dan tujuan dari PBB dan dikutuk oleh "civilized world", dan diperlukan kerjasama internasional untuk memberantasnya. ${ }^{30}$ Sehingga larangan genosida dapat dikatakan memiliki sifat peremptory, yang prinsipnya diakui oleh negara-negara beradab meskipun tanpa kewajiban secara konvensional, karena sifatnya yang "shocks the conscience of mandkind." ${ }^{31}$ Bahkan Statuta Roma menyebut genosida "as one of 'the most serious crimes of concern to the international community as a whole". ${ }^{32}$ Statute Roma juga telah diratifikasi oleh 121 negara. ${ }^{33}$

Hal ini diperkuat oleh Advisory Opinion in the Reservations to the Genocide Convention case, dimana Mahkamah Internasional

29 Prosecutor v. Kambanda (Case No. ICTR-97-23-S), Judgment and Sentence, 4 Sept. 1998 at para.16; Prosecutor v. Serashugo (Case No. ICTR-98-39-S), Sentence, 2 Feb. 1999 at para.15 di dalam Michelle Knorr, The International Crime of Genocide: Obligations Jus Cogens and Erga Omnes, and their Impact on Universal Jurisdiction, p. 32.

30 Preamble of Convention on the Prevention and Punishment of the Crime of Genocide 1948.

31 Rafael, op.cit., p. 27.; Lihat juga Francisco Forrest Martin, Richard J. Wilson, The Rights International Companion to Criminal Law \& Procedure: an International Human Rights and Humanitarian Law Supplement, (The Hague: Kluwer Law International, 1999), p. 342.

32 Article 5 Rome Statute of the International Criminal Court, 1998.

33 United Nations Treaty Collection, "Rome Statute of the International Criminal Court", https://treaties.un.org/ Pages/ViewDetails.aspx?src=TREATY\&mtdsg_no=XVIII-10\&chapter=18\&lang=en, diakses 23 Pebruari 2016. 
memberikan pendapatnya tentang sifat dari prinsip-prinsip yang mendasar yang terkandung di dalam Konvensi Genosida, yaitu: ${ }^{34}$

"...the ICJ indicated that the policies embodied in the Genocide Convention were almost universally demanded, and genocide could therefore be construed as a rule of jus cogens. The Court declared that the principle underlying the Convention are principle which are recognized by civilized nations as binding on states, even without any convention obligation, and stressed the universal character both of the condemnation of genocide and of cooperation required in order to liberate mankind from such an odious scourge."

ICJ juga menyatakan bahwa kewajiban yang terdapat di dalam Konvensi genosida tersebut tidak hanya berlaku terhadap negaranegara pihak konvensi saja, tetapi berlaku terhadap semua negara, sehingga semua negara berkepentingan terhadap kewajibankewajiban konvensi tersebut. Hal tersebut dinyatakan sebagai berikut:

"the prohibition of genocide is binding on all states even without any contractual obligation, reasoning that the Convention was manifestly adopted for a purely humanitarian and civilizing purposes... Its objective on the one hand is to safeguard the very existence of certain human groups and on the other to confirm and endorse the most elementary principles of morality." in such a convention the contracting states do not have any interest of their own; they merely have, one and all, a common interest, namely the accomplishment of those high purposes which are the raison d'etre of the convention." 35

Pencegahan genosida beserta larangannya menyangkut kepentingan bersama masyarakat internasional secara keseluruhan, dibentuk demi tujuan-tujuan kemanusiaan, dan ditempatkan oleh Piagam PBB untuk melawan perjanjian perjanjian atau penggunaan kekerasan dalam hubungan internasional. ${ }^{36}$

Selain itu, bila kita dasarkan analisis pada tujuh kriteria formal dan lima criteria substantive yang ditawarkan oleh Lon Fuller, ${ }^{37}$ maka prinsip larangan genosida ini juga dapat dikatakan sebuah norma jus cogens. Larangan genosida merupakan norma peremptory karena merupakan prinsip umum dan universal, dan bersifat publik. Pencegahan genosida juga bukan merupakan norma yang mustahil atau tidak mungkin untuk dilakukan. Tentu dalam hal ini keinginan serta kemampuan dari negara sangat diperlukan. Selain itu, subyek atau tujuan dari norma genosida tersebut jelas dan tegas, yaitu untuk mencegah dan menindak

34 Reservations to the Convention on the Prevention and Punishment of the Crime of Genocide, Advisory Opinion, ICJ Reports, 1951, p. 15.

35 Ibid.

36 Verdross, “Jus Dispositivium and Jus Cogens in International Law”, AJIL Vol.60, (1996): 217 di dalam International Law in the Post Cold War World, (Routledge Studies of International Law, 2001), p. 503.

37 Lon Fuller, The Morality of Law, rev. edn (New Haven: Yale UP, 1969) di dalam Evan J. Criddle \& Evan FoxDecent, A Fiduciary Theory of Jus Cogens, The Yale Journal of International Law, Vol. 34, (2009): 361-362. 
para pelaku kejahatan genosida. Norma ini juga tidak menentang hukum lainnya dan tidak ada negara yang menentang larangan tersebut. Berkaitan dengan hal ini, dapat dikatakan bahwa mayoritas negara-negara di dunia telah menerima dan mengakui konvensi ini, terbukti bahwa 140 negara merupakan peserta dari konvensi ini. ${ }^{38}$ Banyak statuta internasional juga mengatur larangan genosida ini. ${ }^{39} \mathrm{Hal}$ ini membuktikan bahwa mayoritas negara telah mengikatkan diri terhadap norma dalam konvensi ini.

Sedangkan kriteria substantif, yang mengedepankan moral, bertujuan untuk kebaikan masyarakat serta memperhatikan kepentingan subyek hukum yang sah juga dimiliki oleh konvensi ini. Meskipun konvensi genosida menyebutkan adanya yurisdiksi teritorial, namun hukum kebiasaan internasional juga telah menentukan bahwa terhadap kejahatan genocide berlaku yurisdiksi universal. ${ }^{40}$ Artinya, pengadilan nasional setiap Negara memiliki kompetensi untuk melaksanakan yurisdiksinya untuk mengadili pelaku kejahatan tersebut karena menyangkut umat manusia secara keseluruhan. ${ }^{41}$ Namun tentu Negara yang memiliki yurisdiksi territorial yang memiliki kewenangan tersebut sepanjang mau (willing) dan mampu (able). Pemberlakuannya pun tidak ditentang oleh negara lain. ${ }^{42} \mathrm{Hal}$ tersebut mengindikasikan bahwa semua negara, tanpa terkecuali memiliki kepentingan terhadap pencegahan dan penghukuman kejahatan genosida tersebut. Berdasarkan analisis di atas dapat disimpulkan bahwa genocide merupakan norma jus cogens.

\section{Norma HAM yang melarang penyiksaan}

Yang kedua adalah larangan melakukan penyiksaan (torture) yang pertama kali di diatur dalam Pasal 5 UDHR, yang menyebutkan bahwa: "No one shall be subjected to torture or to cruel, inhuman or degrading treatment or punishment." Prinsip-prinsip di dalam UDHR merupakan hukum kebiasaan internasional. ${ }^{43}$ Pengaturan

38 United Nations Treaty Collection, "Rome Statute of the International Criminal Court", https://treaties.un.org/ Pages/ViewDetails.aspx?src=TREATY\&mtdsg_no=XVIII-10\&chapter=18\&lang=en, diakses 23 Pebruari 2016.

39 Article 2, ICTY Statute 1993, U.N.Doc. S/RES/827; 18 Article 2, ICTR Statute 1994, U.N.Doc. S/RES/955; Articles 5 \& 6, Rome Statute of the ICC 1998 (hereinafter Rome Statute), U.N.Doc.A/CONF.183/9.

40 Mitsue Inazumi, Universal Jurisdiction in Modern International Law: Expansion of National, Jurisdiction for Prosecuting Serious Crimes Under International Law, (Oxford: Intercentia, 2005), pp.150-155; Lihat juga Prosecutor v. Ntuyahaga (Case No. ICTR-90-40-T), Dicision on the Prosecutor's Motion to Withdraw the Indictment, 18 March 1999 di dalam William Schabas, Genocide in International Law : The Crimes of Crimes, (Cambridge: Cambridge University Press, 2000), p. 365.

41 Andrey Sujatmoko, Tanggung Jawab Negara atas Pelanggaran HAM Berat, (Jakarta: Grasindo, 2005), hlm. 76.

42 W. Schabas, Genocide in International Law (Cambridge: Cambridge University Press, 2000), pp. 4-5 di dalam Michelle Knorr, The International Crime of Genocide: Obligations Jus Cogens and Erga Omnes, and their Impact on Universal Jurisdiction, p. 38.

43 Steven Perkins, International Human Rights Law and Article 38 (1) of the Statute of the International Court of Justice, Contemporary Practice of Public International Law, (Dobbs Ferry: Oceana Publications, 1997); Lihat juga Mashood Baderin, Manisuli Ssenyonjo, International Human Rights Law, Six Decades After the UDHR and Beyond, (London: Routledge, 2010), p. 542. 
larangan penyiksaan tersebut kembali diatur di dalam ICCPR, ${ }^{44}$ yang secara eksplisit pada Pasal 4 ayat (2) menyatakan pasal-pasal yang tidak boleh dilanggar (no-derogation) dimana salah satunya adalah pasal tentang larangan melakukan torture. ${ }^{45}$ Negara tidak dapat membebaskan diri sepanjang menyatakan dirinya sebagai anggota dari masyarakat internasional. ${ }^{46}$

Dalam instrumen hukum HAM internasional, penyiksaan pada saat ini secara khusus telah diatur dalam Konvensi Menentang Penyiksaan dan Perlakuan atau Penghukuman Lain yang Kejam, Tidak Manusiawi atau Merendahkan Martabat Manusia 1984. ${ }^{47}$ Sebuah konvensi dapat saja melahirkan norma jus cogens, dimana di dalam konvensi tersebut diatas, larangan terhadap penyiksaan merupakan norma jus cogens. ${ }^{48}$ Karena itu di dalam rezim hukum HAM internasional (international human rights law), hak untuk tidak disiksa memiliki kategori sebagai hakyang tidak boleh dilanggar (non-derogable rights) dalam situasi apapun. Tidak ada keadaan pengecualian apapun, baik keadaan perang atau ancaman perang, ketidakstabilan politik dalam negeri ataupun keadaan darurat, yang dapat digunakan sebagai pembenaran untuk penyiksaan”. Hal ini dinyatakan secara eksplisit di dalam Pasal 2 ayat (2): "No exceptional circumstances whatsoever, whether a state of war or a threat of war, internal political instability or any other public emergency, may be invoked as justification of torture."

Hal tersebut diperkuat dengan jumlah negara sebanyak 150negara merupakan peserta dari konvensi ini. ${ }^{49}$ Di samping itu, pada saat ini penyiksaan atau torture merupakan salah satu kejahatan yang tunduk pada yurisdiksi hukum internasional, sehingga penyelesaiannya dapat berlaku yurisdiksi universal (universal jurisdiction). ${ }^{50}$ Hal tersebut mengindikasikan bahwa larangan penyiksaan bukan lagi hanya

44 International Covenant on Civil and Political Rights 1966.

45 Ibid., Pasal 7.

46 Ibid., Pasal 5 ayat (2).

47 Convention Against Torture and Other Cruel, Inhuman or Degrading Treatment or Punishment, 1984, Pasal 2 ayat (2).

48 United Nations, Committee Against Torture, Convention Against Torture and Other Cruel, Inhuman or Degrading Treatment or Punishment, CAT/C/GC/2, 24 January 2008, General Comment No.2; Lihat juga Siderman de Blake v. Republic of Argentina, 965 F.2d 699, 714 (9th Cir. 1992); Regina v. Bow Street Metro. Stipendiary Magistrate Ex Parte Pinochet Ugarte (No. 3), [2000] 1 AC 147, 198; Lihat juga Restatement (Third) of Foreign Relations Law of the United States 702(d) ("torture or other cruel, inhuman, or degrading treatment or punishment") reporters' note 5 di dalam White Paper on the Law of Torture and Holding Accountable Those Who are Complicit in Approving Torture of Persons in US Custody, National Lawyers Guild International Association of Democratic Lawyers.

49 United Nations Treaty Collection, "Rome Statute of the International Criminal Court", https://treaties.un.org/ Pages $/$ ViewDetails.aspx?src=TREATY\&mtdsg_no $=$ XVIII-10\&chapter $=18 \&$ lang $=$ en, diakses 23 Pebruari 2016.

50 Manfred Nowak, and Elizabeth McArthur, The United Nations Convention Against Torture. A Commentary, (New York: Oxford University Press, 2008); Otto Triffterer. (ed.). Commentary on the Rome Statute of the International Criminal Court. Observers' Notes, Article by Article, (Portland: Hart Publishing Ltd, 2006) di dalam Venues to Combat Impunity of Perpetrators of International Crimes, Global Law Books. 
merupakan urusan internal atau domestik satu negara saja, melainkan semua negara, tanpa terkecuali memiliki kepentingan terhadap norma larangan penyiksaan tersebut.

Isu terkait dengan penyiksaan ini telah dihadapkan kepada sejumlah organ hak asasi manusia, seperti Human Rights Committee, the European Court of Human Rights, and the International Criminal Tribunal on the Former Yugoslavia. ${ }^{51}$ Dalam kaitan dengan hal tersebut maka: ${ }^{52}$

"The ban on torture, for instance, binding not just on the states parties to the 1984 United Nations Convention against torture and other cruel, inhuman or degrading punishments or treatment, but also on the whole international community, since it is a binding norm of general international law. The regulation by convention banning torture is undoubtedly more specific, apart from the fact that it institutes a number of specific guarantee procedures."

Hal ini berarti larangan penyiksaan merupakan prinsip dalam hukum internasional, yang memiliki status jus cogens, sehingga mengikat komunitas internasional secara keseluruhan, baik negara yang merupakan peserta dari Konvensi tersebut maupun yang bukan. ${ }^{53}$ ICTY juga menyatakan bahwa:
Because of the importance of the values it protects, this principle has evolved into a peremptory norm or jus cogens, that is, a norm that enjoys a higher rank in the international hierarchy than treaty law and even "ordinary" customary rules. The most conspicuous consequence of this higher rank is that the principle at issue cannot be derogated from by States through international treaties or local or special customs or even general customary rules not endowed with the same normative force $^{54}$

Hal tersebut berarti ICTY menganggap bahwa torture merupakan jus cogens karena ada nilai fundamental yang dilindungi (pelanggaran terhadap penyiksaan) yang telah berevolusi menjadi norma yang memiliki kekuatan memaksa atau jus cogens, sehingga larangan penyiksaan menjadi salah satu standar fundamental komunitas internasional.

\section{Norma HAM yang melarang diskriminasi ras}

HAM berikutnya adalah larangan melakukan diskriminasi yang diatur di dalam International Convention on the Elimination of All Forms of Racial Discrimination 1965. Pada preambul disebutkan bahwa:

$$
\begin{aligned}
& \text { ".....necessity of speedily } \\
& \text { eliminating racial discrimination } \\
& \text { throughout the world in all its }
\end{aligned}
$$

51 Malcolm Shaw, Ibid.

52 Human Righti Committee, General Comment No. 24 (52), CCPR/C/2 I/Rev. I/Add. 6, adopted by the Committee on 2 November 1994 di dalam Juan Antonio Carrillo Salcedo, "Reflections on the Existence of a Hierarchy of Norms in International Law", European Journal of International Law, (1997): 594.

53 Ibid.

54 Prosecutor v. Furund`zija, Case No. IT-95-17/1-T, Judgment, 153 (Dec. 10, 1998). 
forms and manifestations.... that there is no justification for racial discrimination, in theory or in practice, anywhere,.... adopt all necessary measures for speedily eliminating racial discrimination in all its forms and manifestations, and to prevent and combat racist doctrines and practices in order to promote understanding between races and to build an international community free from all forms of racial segregation and racial discrimination."

Prinsip larangan "racial discrimination" ini telah diakui sebagai hukum kebiasaan internasional. ${ }^{55}$ Bahkan, prinsip tersebut juga telah diakui sebagai norma jus cogens, ${ }^{56}$ karena memiliki nilai universal dan berlaku untuk komunitas internasional, yang dapat dilihat pada bagian preambul diatas. Saat ini sebanyak 175 negara merupakan peserta dari konvensi tersebut. ${ }^{57}$

Non-discrimination merupakan sebuah norma yang bersifat mandatory atau memaksa. norma tersebut juga berhubungan secara langsung dengan kepentingan masyarakat yang luas berdasarkan kepentingan publik.
Kriteria substantif yang dimiliki oleh norma ini juga berisi tentang kewajiban negara untuk menjamin dan memastikan tatanan hukum. Terlebih lagi norma ini sangat penting dan diciptakan untuk tujuan kemanusiaan. ${ }^{58}$ Sehingga memenuhi kriteria sebagai norma jus cogens.

Bila melihat norma-norma HAM di atas, terlihat bahwa proses "law making" dari sebuah perjanjian multilateral is legislative in objective dan hanya bersifat kontraktual dalam metodenya saja. Itulah bagaimana norma-norma non-derogable yang berasal dari perjanjian yang hampir diterima secara universal, baik diadopsi oleh mayoritas negara, telahmenjadi normajus cogens. Hal itulah yang terjadi pada prinsip larangan genosida, ${ }^{59}$ dan larangan penyiksaan, ${ }^{60}$ yang didasarkan pada sejumlah perjanjian internasional dan resolusi Majelis umum terkait dekolonisasi. ${ }^{61}$ Berbeda dengan hukum kebiasaan internasional yang memperbolehkan suatu negara untuk menolak aturan tersebut (persistent objector), jus cogens memaksa negara penolak tersebut untuk taat. ${ }^{62}$ Itulah sebabnya ada yang

55 McKean, W., Equality and Discrimination under International Law, (Oxford: Clarendon Press, 1983), pp. 271-277 di dalam The fight against racism: Principles of non-discrimination and equality, Australian Human Rights Commission, 2000.

56 Ian Brownlie, Principles of Public International Law, 3rd edition, (Oxford: Clarendon Press, 1979), pp. 596598.

57 United Nations Treaty Collection, "Rome Statute of the International Criminal Court", https://treaties.un.org/ Pages/ViewDetails.aspx?src=TREATY\&mtdsg_no=XVIII-10\&chapter=18\&lang=en, diakses 23 Pebruari 2016.

58 A. Verdross, “Jus Dispositivum and Jus Cogens in International Law”, AJIL Vol. 60, (1966): 59.

59 Convention on the Prevention and Punishment of the Crime of Genocide 1948, Pasal 1.

60 Convention against torture and other cruel, inhuman or degrading treatment or Punishment 1984, Pasal 2 dan 3.

61 F. Martin, International Human Rights and Humanitarian Law, (New York: Cambridge University Press, 2006), p. 35.

62 Human Rights Committee, International Law Association (British Branch), Report on Civil Actions in the English Courts for Serious Human Rights Violations Abroad, EUR. HUM. RTS. L. REV., 200, di dalam Stacy Humes-Schulz, "Limiting Sovereign Immunity in the Age of Human Rights", Harvard Human Rights Journal Vol. 21, (2008): 110. 
menyebut bahwa opinio juris yang berlaku pada hukum kebiasaan internasional, harus berlaku juga pada jus cogens, tetapi bersifat "double opinio juris." 63

Aspek lain yang dimiliki oleh jus cogens adalah kewajiban erga omnes. Di dalam putusannya pada kasus Barcelona Traction, tanggal 5 Februari 1970, walaupun tidak secara tegas menggunakan istilah jus cogens, ICJ secara eksplisit menyatakan eksistensi jus cogens dengan pengertian "obligation erga omnes." Dalam kasus tersebut, ICJ menyatakan bahwa:

\section{[A]n essential distinction should} be drawn between the obligations of a State towards the international community as a whole, and those arising vis-à-vis another State.... $B y$ their nature the former are the concern of all States. In view of the importance of the rights involved, all States can be held to have a legal interest in their protection; they are obligations erga omnes.... Such obligations derive, for example, in contemporary international law, from the outlawing of acts of aggression, and of genocide as also from the principles and rules concerning the basic rights of the human person, including protection from slavery and racial discrimination.
Dari pernyataan ICJ diatas, "obligation erga omnes" diartikan sebagai "the obligation of a state towards the international community as a whole," dimana ICJ membedakannya dengan "those existing vis-à-vis another state..." By their very nature the former are the concern of all States. ... all States can be held to have a legal interest in their protection; they are obligations erga omnes. ${ }^{64}$ Adapun erga omnes merupakan istilah yang digunakan untuk menggambarkan "kewajiban terhadap masyarakat internasional. " 65

Misalnya negara dapat dikatakan melanggar kewajiban erga omnes karena negara membiarkan terjadinya atau bahkan melakukan kejahatan internasional yang merupakan jus cogens; dan atau negara tersebut gagal atau tidak mau menuntut pertanggungjawaban dari para aparat negara pelaku tindak kejahatan tersebut. Padahal mengadili para pelaku kejahatan internasional merupakan sebuah keharusan mutlak karena para pelaku tersebut merupakan musuh bersama seluruh umat manusia (hostis humanis generis). Dengan demikian, dapat dilihat bahwa hubungan antara jus cogens dan erga omnes adalah erat karena jus cogens merupakan status dari sebuah kejahatan internasional, seperti genosida.

63 Lihat Linderfalk, Legal Discourse Gone Awry: Why the Scholarly Debate on the Legality of Operation Enduring Freedom Was Poor Science, 2008 di dalam Ulf Linderfalk, "The Effect of Jus Cogens Norms: Whoever Opened Pandora's Box, Did You Ever Think About the Consequences?", The European Journal of International Law Vol. 18 No.5, (2008): 862, diakses 23 Pebruari 2016, doi: 10.1093/ejil/chm044.

64 Case Concerning Barcelona Traction, Light and Power Company Ltd, (Belgium v. Spain: ICJ Reports, 1970), p. $3,30$.

65 Andre de Hoogh, Obligations Erga Omnes and International Crimes, A Theoritical Inquiry into the Implementation and Enforcement of the International Responsibility of States, (The Hague: Kluwer Law International, 1996), p. 53; Lihat jugaThe Genocide case (Bosnia nad Herzegovina v. Yugoslavia), ICJ Reports, 1996, p. 615. 
Sedangkan erga omnes merupakan dampak atau akibat hukum yang timbul dari karakteristik sebuah kejahatan yang berstatus jus cogens. ${ }^{66}$ Dengan mengakui sebuah kejahatan sebagai jus cogens, maka ada kewajiban ergaomnes, seperti kewajiban untuk mengekstradisi, kewajiban tidak memberikan kekebalan kepada pelaku kejahatan tersebut, ${ }^{67}$ dan dapat berlakunya yurisdiksi universal. ${ }^{68}$

Memang dapat dikatakan bahwa semua norma jus cogens menimbulkan kewajiban erga onmes, tetapi masih diperdebatkan bahwa tidak semua kewajiban erga onmes berasal dari norma jus cogens. Sebagai contoh, semua norma tentang hak asasi manusia yang telah bersifat hukum kebiasaan menimbulkan kewajiban erga omnes, tetapi tidak semua hak asasi manusia tersebut merupakan sebuah norma jus cogens. ${ }^{69}$

Selain putusan dan pendapat dari badan peradilan internasional, beberapa judge peradilan tersebut juga menyatakan pendapat mereka tentang status HAM sebagai jus cogens. Seperti yang ditekankan oleh Judge Tanakan, di dalam dissenting opinion nya dalam kasus South West Afrika, yang berpendapat bahwa
HAM dapat dianggap sebagai jus cogens bila negara-negara mampu mengubah cara mereka membuat kesepakatan:

If we can introduce in the
international field a category of
law, namely jus cogens, recently
examined by ILC, a kind of
imperative law which constitutes
the contrast to jus dispositivum,
capable of being changed by way
of agreement between States, surely
the law concerning the protection of
human rights may be considered to
belong to the jus cogens.

Selain Judge Tanakan, Judge Weeramantry, di dalam dissenting opinion, menyatakan bahwa aturan dan ketentuan hukum humaniter telah secara jelas mencapai status jus cogens. ${ }^{71}$ Judge Koroma, di dalam dissenting opinion, memberikan catatan bahwa "already in the 1980, the Commission observed that some of the rules of humanitarian law are, in the opinion of the International Law Commission, rules which impose obligation of jus cogens. "72 Aturan-aturan fundamental tersebut harus diakui dan diikuti oleh semua negara karena mereka merupakan bentuk hukum kebiasaan internasional. $^{73}$

66 M. Cherif Bassiouni, "International Crimes: Jus Cogens and Obligation Erga Omnes", Law and Contempory Problems, Vol. 59, No. 4, (1996): 66.

67 Ibid.

68 M. Cherif Bassiouni, op.cit., p. 66.

69 M. Bassiouni, Introduction to International Criminal Law, (New York: Transnational Publishers Inc., 2003), p. 177 di dalam Michelle Knorr, The International Crime of Genocide: Obligations Jus Cogens and Erga Omnes, and their Impact on Universal Jurisdiction, p. 36; Lihat juga Barcelona Traction, Light and Power Company Ltd., Judgment, 1970 (ICJ. Rep. 3) at paras. 33-34.

70 Judge Tanaka's Dissenting Opinion in the South West Africa case (Ethiopia v. South Africa; Liberia v. South Africa), Second Phase, Judgment [1966] ICJ Rep 298.

71 Advisory Opinion, Dissenting Opinion of Judge Weeramantry, p. 46.

72 Ibid., Dissenting Opinion if Judge Koroma, pp. 13-14.

73 Laurence Boission de Chazaurnes, Philippe Sands, International Law, The International Court of Justice and Nuclear Weapons, (Cambridge: Cambridge University Press, 1999), p. 183. 
Dari penjelasan diatas, dapat dilihat bahwa memang tidak semua hak asasi manusia dapat dikategorikan sebagai norma jus cogens. Untuk menjadi norma jus cogens, hak asasi tersebut harus berhubungan langsung dengan kepentingan masyarakat internasional secara keseluruhan dan juga merupakan norma yang "shock the conscience of mandkind". ${ }^{74}$

Terdapat beberapa contoh HAM yang sifatnya tidak kontroversial seperti hak-hak lainnya dan telah disepakati dan diakui sebagai jus cogens, diantaranya, ${ }^{76}$ prohibition of genocide, ${ }^{76}$ prohibition of discrimination on the basis of race, color, sex, language, religion, or social origin ${ }^{77}$ prohibition of crimes against humanity, ${ }^{78}$ prohibition of war crimes, ${ }^{70}$ use offorce, ${ }^{80}$ prohibition of slavery, ${ }^{81}$ the right to humane treatment, ${ }^{82}$ prohibition of imprisonment for civil debt, ${ }^{83}$ the right to self determination, ${ }^{84}$ dan piracy, ${ }^{85}$
Sehingga tampaknya norma yang telah diterima secara umum yang memiliki derajat jus cogens meliputi:

1. Norma-norma fundamental mengenai pemeliharaan perdamaian, seperti larangan penggunaan kekuatan bersenjata atau use of force;

2. Norma-norma fundamental dari suatu kodrat kemanusiaan seperti larangan genosida, larangan penyiksaan, perbudakan, diskriminasi rasial, pembersihan etnik atau ethnic cleansing, hak untuk menentukan nasib sendiri atau self-determination, perlindungan hak-hak asasi manusia pada masa perang dan damai, norma yang melarang setiap pelanggaran terhadap kemerdekaan dan persamaan kedaulatan negara-negara'

3. Norma-norma yang menjamin semua anggota masyarakat internasional untuk

74 Francisco Forrest Martin, Richard J. Wilson, The Rights International Companion to Criminal Law \& Procedure: an International Human Rights and Humanitarian Law Supplement, (The Hague: Kluwer Law International, 1999), p. 342.

75 Draft Articles on State Responsibility, Commentary on Article 40, paras. 4-6 in Official Records of the General Assembly, Fifth-sixth Session (A/56/10) pp. 283-284; Fiona de Londras, The Religiosity of Jus Cogens, A Moral Case for Compliance, 2007, p. 253.

76 Convention on the Prevention and Punishment of the Crime of Genocide, art 1.

77 Judge Tanaka, Dissenting Opinion, South West Africa Caes (Second Phase), ICJ Reports, 1966; Judge Ammoun, Separate Opinion, Barcelona Traction Case (Second Phase), ICJ Reports, 1970 di dalam Ian Brownlie, op.cit., hlm. 498.

78 Statute of the International Criminal Court, art. 7.

79 Geneva Convention IV, arts. 146, 149.

80 Yearbook of the ILC, 1966, Vol. 11, p. 248. Di dalam Malcolm N. Shaw, International Law, Third Edition, (Cambridge: Cambridge University Press, 1991), p. 117.

81 ICCPR, art. 8; ECHR, 64, art. 4; ACHR, art. 6.

82 ICCPR, art. 7; European Convention for the Protection of Human Rights and Fundamental Freedoms, art. 3 , American Convention on Human Rights, art. 5.

83 ICCPR, art. 11.

84 Western Sahara, advisory opinion, based on a series of General Assembly resolutions and state practice of decolonization; Lihat juga Predrag Zenovic, "Human Rights Enforcement via Peremptory Norms - a Challenge to State Sovereignty", RGLS Research Papers, No. 6, (2012): 35.

85 Inter-American Commission of Human Rights in the Case of Roach and Pinkerton, Decision 27 Merch 1987 (OAS General Secreatriat); Ian Brownlie, Principles of Public International Law, (New York: Oxford University Press, 1979), p. 512. 
menikmati sumber daya alam bersama, laut lepas, ruang angkasa, dll.

Keterangan diatas menunjukan bahwa di tengah-tengah kesulitan mengidentifikasi kriteria untuk menentukan norma-norma yang bersifat jus cogens, dalam kenyataannya masyarakat internasional telah menentukannya sesuai dengan taraf perkembangan dan kebutuhan akan norma tersebut dalam hubungan hukum masyarakat internasional. ${ }^{86}$ Tanpa mengabaikan berbagai persoalan dan kontroversi yang muncul berkaitan dengan jus cogens, dapatlah dikatakan bahwa eksistensi jus cogens telah diterima dan diakui. Hal tersebut terlihat di dalam praktek negara, hukum perjanjian yang telah terkodifiaksi, pengadilan nasional dan internasional, dan oleh teori hukum. ${ }^{87}$

Untuk itu, dapat disimpulkan dari berbagai kriteria yang telah diberikan oleh sejumlah ahli dalam menentukan sebuah norma sebagai jus cogens, hendaknya melihat aspek formal yaitu sebuah kondisi yang membentuk norma tersebut, dan aspek substantif, dimana norrma tersebut memiliki substansi yang memaksa. Aspek-aspek tersebut dapat dilihat dari hal-hal berikut yaitu: ${ }^{88}$

a. Pengakuan internasional atau yang biasa disebut sebagai opinio juris yang menerima dan mengakui sebuah norma sebagai norma yang berlaku umum dan universal; dalam arti bahwa tidak ada negara secara individual memiliki hak untuk menggunakan hak veto norma jus cogens. ${ }^{89}$

b. Bahasa di dalam sejumlah konvensi atau perjanjian internasional, baik di dalam preambul maupun pasalpasal, yang mengindikasikan norma tersebut kedudukannya "lebih tinggi" dibandingkan dengan norma lain,

c. Mayoritas (jumlah) negara yang telah meratifikasi perjanjian tentang norma jus cogens tersebut;

d. Analisis serta putusan-putusan badan atau peradilan internasional terkait norma tersebut.

\section{Simpulan}

Dari keseluruhan penjelasan dan analisis yang telah dipaparkan diatas, maka jurnal ini menghasilkan beberapa kesimpulan.

1. Untuk menentukan kriteria norma jus cogens, dapat dilakukan dengan melihat aspek formal yang memastikan bahwa norma peremptory tersebut merupakan sebuah prinsip umum yang memiliki sifat publik, layak, jelas, konsisten, prospektif dan stabil, yang dapat digunakan oleh negara-negara untuk mengatur dan merepresentasikan rakyatnya, serta aspek

86 G.J.H Van hoof, Rethinking the Sources of International Law, diterjemahkan oleh Hata dalam Pemikiran Kembali Sumber-sumber Hukum Internasional, (Bandung: Alumni, 2000), hlm. 318, di dalam Andrey Sujatmoko, Jus Cogens dan Kaitannya dengan Beberapa Perjanjian Internasional, hlm. 9.

87 Nina Jorgensen, The Responsibility of States for International Crime, (New York: Oxford University Press, 2000), p. 89. di dalam Andrey Sujatmoko, Ibid., hlm. 9.

88 M. Cherif Bassiouni, "International Crimes: Jus Cogens and Obligation Erga Omnes”, Law and Contempory Problems, Vol. 59, No.4, (1996): 68.

89 Ian Sinclair, op.cit., p. 127. 
substantif, yang berhubungan dengan struktur maupun isi yaitu integritas, adil, bersifat fundamental dan mendasar. Kriteria tersebut dapat dijadikan dasar karena membedakan kriteria berdasarkan karakter maupun pemenuhan kriteria yang diperlukan.

2. Memang tidak semua hak asasi manusia dapat dikategorikan sebagai norma jus cogens. Untuk menjadi norma jus cogens, norma HAM tersebut harus memenuhi beberapa kriteria diatas yaitu kriteria dari aspek formal maupun substantif. Tentu norma HAM tersebut harus berhubungan langsung dengan kepentingan masyarakat internasional secara keseluruhan dan merupakan norma yang "shock the conscience of mandkind'. Selain itu dengan semakin banyaknya instrumen hukum yang melarang kejahatan tersebut serta jumlah negara yang telah meratifikasinya dan menerapkannya ke dalam hukum nasionalnya, akan semakin mudah untuk mengkategorikan norma tersebut sebagai jus cogens. Terdapat beberapa HAM yang sifatnya tidak sekontroversial lainnya dan telah disepakati dan diakui sebagai jus cogens, diantaranya, prohibition of genocide, prohibition of discrimination on the basis of race, color, sex, language, religion, or social origin, prohibition of crimes against humanity, prohibition of war crimes, use of force, prohibition of slavery, the right to humane treatment, prohibition of imprisonment for civil debt, the right to self determination, dan piracy.

\section{DAFTAR PUSTAKA}

\section{Buku}

Baderin, Mashood and Manisuli Ssenyonjo. International Human Rights Law, Six Decades After the UDHR and Beyond. England: Ashgate Publishing, 2010.

Brownlie, Ian. Principles of Public International Law. 3rd edition. Oxford: Clarendon Press Oxford, 1979.

Principles of Public International Law. Fifth Edition. New York: Clarendon Press, 1998.

Chazaurnes, Laurence Boission de and Philippe Sands. International Law,
The International Court of Justice and Nuclear Weapons. Cambridge: Cambridge University Press, 1999.

Coghill, Ken dkk. Fiduciary Duty and the Atmospheric Trust. England: Ashgate Publishing Limited, 2012.

Hoof, Van. Rethinking the Sources of International Law. Authorized translation from English language. Bandung: Yayasan Hak Asasi Manusia Demokrasi dan Supremasi Hukum, 2000. 
Inazumi, Mitsue. Universal Jurisdiction in Modern International Law: Expansion of National, Jurisdiction for Prosecuting Serious Crimes Under International Law. Oxford: Intercentia, 2005.

Martin, F. International Human Rights and Humanitarian Law. New York: Cambridge University Press, 2006.

Martin, Francisco Forrest and Richard J. Wilson. The Rights International Companion to Ccriminal Law \& Procedure: an International Human Rights and Humanitarian Law Supplement. New York: Kluwer Law International, 1999.

Nowak, Manfred and Elizabeth McArthur. The United Nations Convention Against Torture. A Commentary. New York: Oxford University Press, 2008.

Pauwelyn, Joost. Conflict of Norm in Public International Law, How WTO Law Relates to Other Rules of International Law". Cambridge: Cambridge University Press, 2003.

Sefriani. Hukum Internasional: Suatu Pengantar. Jakarta: RajaGrafindo Persada, 2009.

Sinclair, Ian. The Vienna Convention on the Law of Treaties. UK: Manchester University Press, 1973.

Starke, J.G. Pengantar Hukum Internasional.

Edisi Ke-10. Jakarta: Sinar Grafika, 1995.

Thirlway, Hugh. The Sources of International Law. Foundation of Public International Law: Oxford University Press, 2014.

\section{Jurnal}

Bassiouni, M. Cherif. "International Crimes: Jus Cogens and Obligation Erga Omnes". Law and Contempory Problems, Vol. 59, No.4, (1996): 66.

Criddle, Evan J. \& Evan Fox-Decent. "A Fiduciary Theory of Jus Cogens". The Yale Journal of International Law, Vol. 34, (2009): 361-362.

Danilenko, Gennady. "International Jus Cogens: Issues of Law Making”. European Journal of International Law, Vol. II, No.1, (1991): 2.

Linderfalk, Ulf . "The Effect of Jus Cogens Norms: Whoever Opened Pandora's Box, Did You Ever Think About the Consequences?". The European Journal of International Law Vol. 18, No.5, (2008): 862. Diakses 23 Pebruari 2016. Doi: 10.1093/ejil/chm044.

Magallona, Merlin. "The Concept of Jus Cogens in the Vienna Convention on the Law of the Treaties". Phillippine Law Journal, Vol. 51, (1976): 521.

Salcedo, Juan Antonio Carrillo. "Reflections on the Existence of a Hierarchy of Norms in International Law". European Journal of International Law, (1997): 594.

Verdross, A. "Jus Dispositivum and Jus Cogens in International Law". AJIL Vol. 60, (1966): 59. 


\section{Konvensi}

Convention Against Torture and Other Cruel, Inhuman or Degrading Treatment or Punishment, 1984.

International Covenant on Civil and Political Rights, 1966.

Rome Statute of the International Criminal Court, 1998.
The Convention on the Prevention and Punishment of the Crime of Genocide 1948.

The Vienna Convention on the Law of Treaties 1969.

The Vienna Convention on the Law of Treaties Between States and International Organizations or Between International Organizations, 1986. 